Chir. plastica (Berl.) 3, 23-26 (1975)

(C) by Springer-Verlag 1975

\title{
Reconstruction of the Lower Lip
}

\author{
Menachem Ron Wexler* and Reed O. Dingman**
}

Received June 25, 1974

Summary. A method for reconstruction of the lower lip following larger subtotal excision is described. The method is based on the principle introduced by Stein and modified by Estlander, Abbe, Kazanjian, and Converse, and seems to be especially valid in cases of older patients with redundant upper lip tissue. One case is presented.

A case is presented in which the lower lip was subtotally excised for squamous cell carcinoma and reconstructed by bilateral Stein-Estlander-Abbe flaps.

\section{Case Report}

A 79 year old white male was admitted for treatment of squamous cell carcinoma of the lower lip. Twenty-eight years prior to admission he was treated for squamous cell carcinoma of the lower lip by radium needle implantation and bilateral submaxillary lymph node dissection. Following the irradiation treatment, the patient could not bring his lips together. One year prior to his present admission, a lesion developed on the lower lip and failed to heal. Physical examination was within normal limits otherwise (Fig. 1). The medial segment of the lower lip was somewhat hardened; no lymph nodes were palpated in the neck. Following consultation with a radiologist and dermatologist, wide local excision of the lower lip was performed under local anesthesia (Fig. 2).

The specimen margins were examined by frozen section technique. Following negative results from the pathologists, two large Stein-Estlander-Abbé flaps were rotated downward,

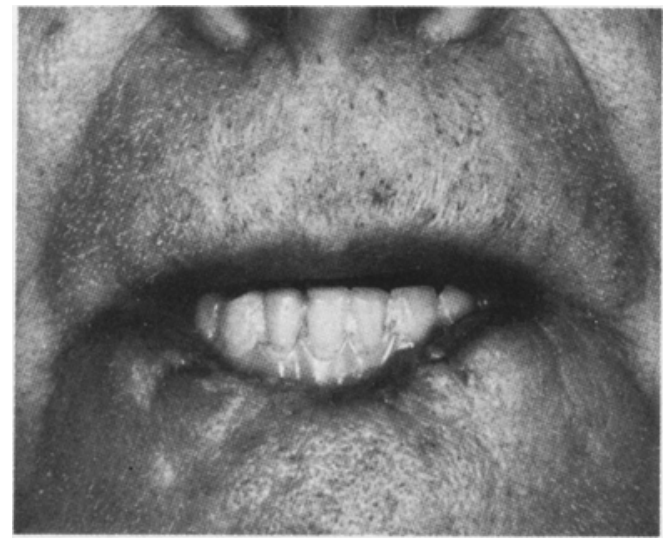

Fig. 1. Defect of lower lip with recurrent squamous cell carcinoma 28 years following treatment by radium needle implantation

\footnotetext{
* Department of Plastic Surgery, Hadassah University Hospital, Jerusalem, Israel. Former resident in Plastic Surgery, University of Michigan Medical Center, Ann Arbor, Michigan.

** Professor of Surgery and Head, Section of Plastic Surgery, University of Michigan Medical Center, Ann Arbor Michigan 48104.
} 


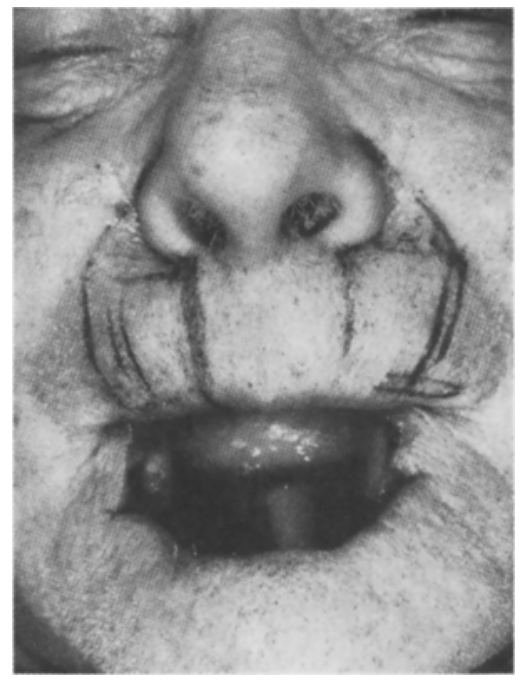

Fig. 2. The patient following subtotal excision of the lower lip and outlining of crossed lip flaps on the left side. The position of the superior labial artery is outlined

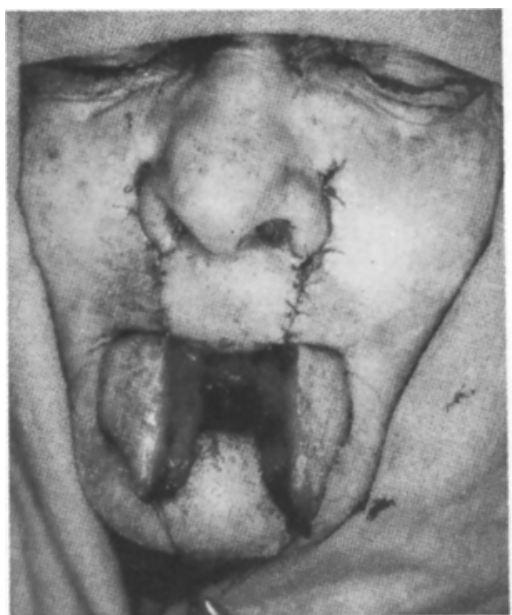

a

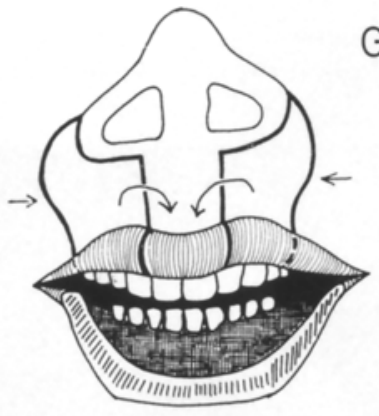

G

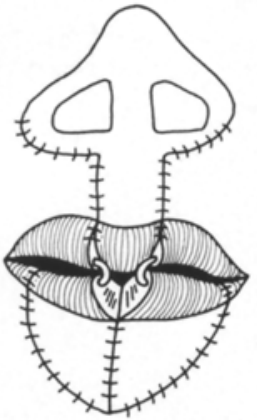

b

Fig. 3 a. The two flaps have been cut except for the vascular bundle. The mucosa is cut completely, as well as the vermilion, leaving only the labial vessels intact. Donor sites have been closed

Fig. 3 b. Diagrammatic plan of flaps as developed and rotated into the lower lip

hinged laterally on the labial arteries and separating all the mucosal border (Fig. 3). Each flap measured $2.2 \mathrm{~cm}$, thus reducing the upper lip to half of its $10 \mathrm{~cm}$ when stretched. Approximately $1 \mathrm{~cm}$ was preserved in the lower lip at each angle.

Several days after operation the final pathology report arrived disclosing that tumor cells were found in the muscle layer, despite the previous negative frozen section report. 


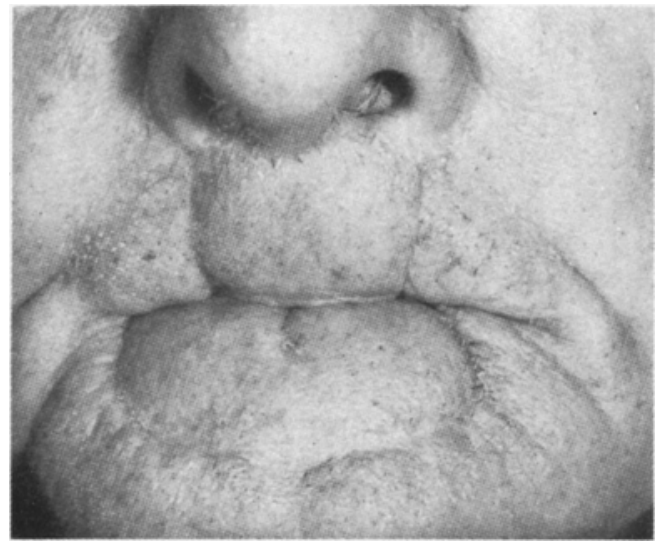

Fig. 4. Reconstructed lower lip 3 months postoperative
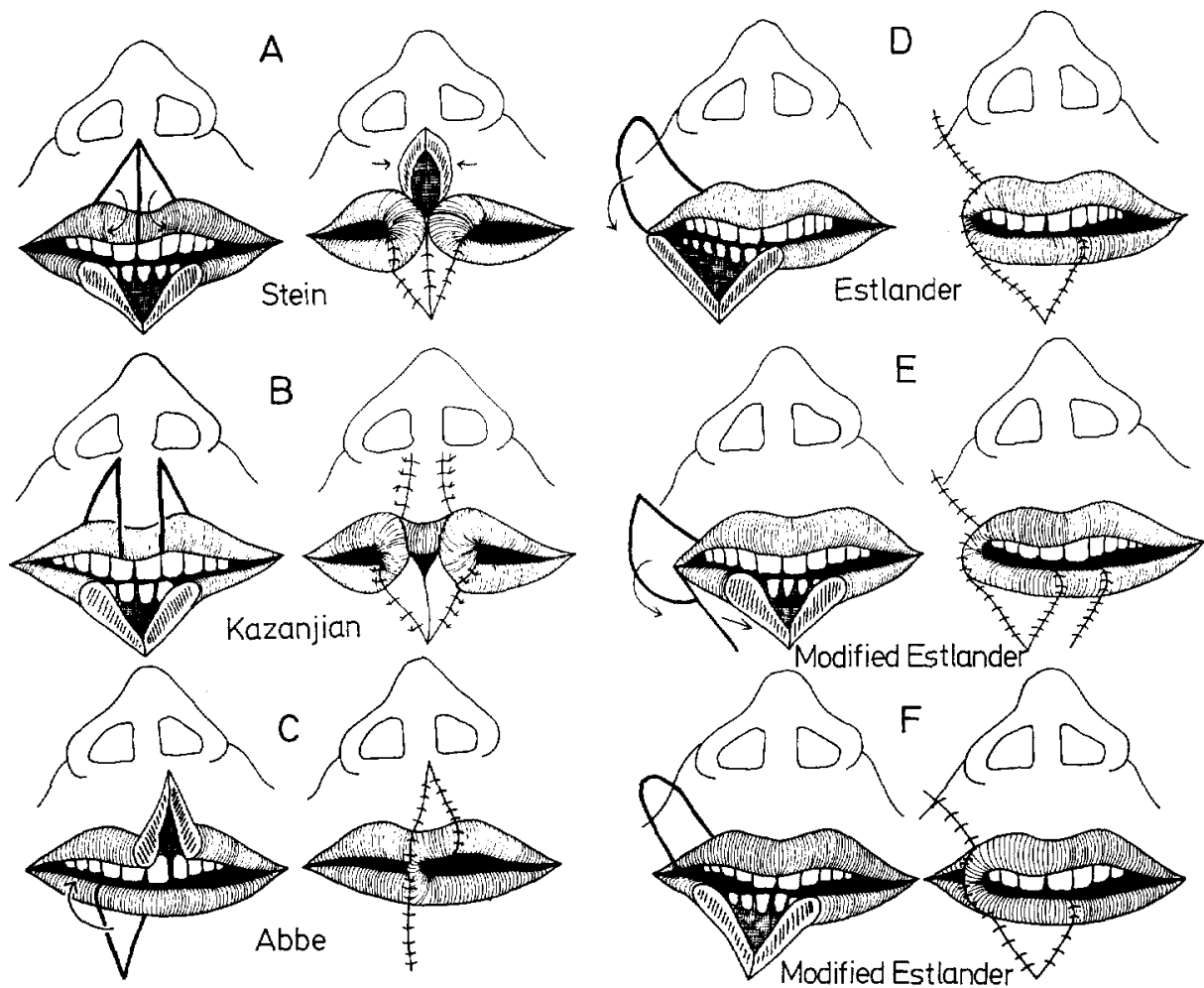

Fig. 5. $A$ to $F$ : Various plans of lip reconstruction with switched flaps

The patient was returned to the operating room where the flaps were separated and wider excision was obtained from the lower lip. The flaps were reapproximated.

Two weeks following the second operation the labial arteries were cut and the final adjustments made. The patient is shown 3 months after operation in Fig. 4. 


\section{Discussion}

In 1848 , Stein $[1,2]$ used two triangular flaps from the midline of the upper lip to reconstruct the lower lip. In 1865 Estlander $[1,2]$ used a triangular flap from the nasolabial sulcus area and rotated the angle of the mouth with the flap for reconstruction. Kazanjian [2] modified Stein's original operation by taking the flaps laterally to the philtrum. A further modification of the Estlander-Abbe flap was advocated by Converse [2] for repair of small defects of the lower lip, leaving the corner of the mouth intact with an oblique scar in the upper lip. Murphy [3] modified the Estlander operation by adding two lateral flaps transposed medially (Fig. 5 A-F).

In all of the above methods upper lip tissue was used to reconstruct the lower lip. The experimental and clinical work concerning renervation of denuded muscle by Thompson [4-6] explains the good muscular activity of the SteinEstlander-Abbe flap.

In our ease a subtotal defect of the lower lip was reconstructed, obtaining a combined width of $4.4 \mathrm{~cm}$ with both flaps. The flap extended beyond the gingivobuccal sulcus (Fig. 3) yielding more skin and thus increasing the potential indications for this kind of flap.

The advantages of this procedure are: 1) preservation of the commissure of the mouth, 2) local tissue is used to equalize both upper and lower lips, 3) procedure can be done under local anesthesia, and 4), there is minimal blood loss.

The disadvantages are: 1) two stages are required, 2) the mouth is almost closed for 2 weeks, 3), there is transient numbness of the lower lip, and 4) the resulting smaller oral opening may be a problem to denture wearers.

\section{References}

1. Fogh-Anderson, P.: Stein-Estlander-Abbé operation. A centenary in plastic surgery. Plast. reconstr. Surg. S, 186-188 (1948)

2. Converse, J. M.: Reconstr. plast. Surg. 2, 848-850 (1964)

3. Murphy, A. L.: An operative procedure for cancer of the lip. Surg. Gynec. Obstet. 111, 786-787 (1960)

4. Thompson, N., Pollard, A. C.: Motor function in Abbe flaps. A histochemical study of motor reinnervation in transplanted muscle tissue of the lips in man. Brit. J. plast. Surg. 14, 66-75 (1961)

5. Thompson, N.: Autogenous free grafts of skeletal muscle-a preliminary experimental and clinical study. Plast. reconstr. Surg. 48, 11-27 (1971)

6. Thompson, N.: Treatment of facial paralysis by free skeletal muscle grafts. Fifth World Congress of Plast. reconstr. Surg. p. 66-82: Butterworths 1971

Menachem Ron Wexler, M.D.

Department of Plastic Surgery

Hadassah Medical Organization

Kiryat Hadassah

Jerusalem, Israel 